\title{
Determination of S-112 and Mock Tank Electrical Resistivities using Numerical Forward and Inverse Solutions
}

\author{
A. Ramirez, and W.D. Daily
}

May 1, 2002

U.S. Department of Energy

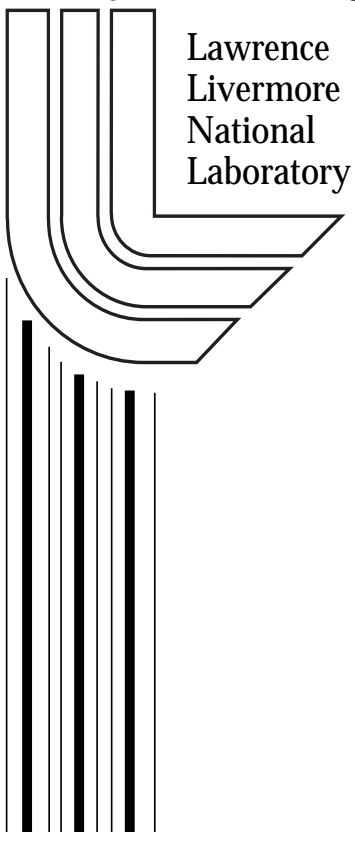




\section{DISCLAIMER}

This document was prepared as an account of work sponsored by an agency of the United States Government. Neither the United States Government nor the University of California nor any of their employees, makes any warranty, express or implied, or assumes any legal liability or responsibility for the accuracy, completeness, or usefulness of any information, apparatus, product, or process disclosed, or represents that its use would not infringe privately owned rights. Reference herein to any specific commercial product, process, or service by trade name, trademark, manufacturer, or otherwise, does not necessarily constitute or imply its endorsement, recommendation, or favoring by the United States Government or the University of California. The views and opinions of authors expressed herein do not necessarily state or reflect those of the United States Government or the University of California, and shall not be used for advertising or product endorsement purposes.

This work was performed under the auspices of the U. S. Department of Energy by the University of California, Lawrence Livermore National Laboratory under Contract No. W-7405-Eng-48.

This report has been reproduced directly from the best available copy.

Available electronically at http://www.doc.gov/bridge

Available for a processing fee to U.S. Department of Energy

And its contractors in paper from

U.S. Department of Energy

Office of Scientific and Technical Information

P.O. Box 62

Oak Ridge, TN 37831-0062

Telephone: (865) 576-8401

Facsimile: (865) 576-5728

E-mail: reports@adonis.osti.gov

Available for the sale to the public from

U.S. Department of Commerce

National Technical Information Service

5285 Port Royal Road

Springfield, VA 22161

Telephone: (800) 553-6847

Facsimile: (703) 605-6900

E-mail: orders@ntis.fedworld.gov

Online ordering: http://www.ntis.gov/ordering.htm

OR

Lawrence Livermore National Laboratory

Technical Information Department's Digital Library

http://www.llnl.gov/tid/Library.html 


\title{
Determination Of S-112 And Mock Tank Electrical Resistivities Using Numerical Forward And Inverse Solutions
}

\author{
A. L. Ramirez and W. D. Daily \\ Lawrence Livermore National Laboratory \\ May, 2002
}

\section{Purpose}

The purpose of this work is to establish the electrical similarity of the Mock Tank site to S-112 tank site to determine if the Mock Tank requires modifications for the tests this summer. We accomplish this objective by determining the effective electrical resistivity of S-112 and comparing it with that of the Mock Tank. We also compare the expected sensitivities under S-112 and Mock Tank assuming that long electrodes are used.

\section{Measurements made}

Resistance measurements were made on 4/8/02 in the vicinity of S-112 using nearby dry wells as long electrodes. In addition, thermocouple trees in some of the tanks were used as electrodes (only as receivers, not as transmitters); we expect that when a thermocouple tree is used, the whole tank becomes an electrode.

All measurements were made with the Zonge data acquisition system owned by LLNL. An analogue ohm meter was also used to make some 2 pole measurements. We use 4 pole measurements exclusively for the analysis reported herein. Figure 1 shows the tank and dry well layout in plan view.

Point electrodes were also deployed along the surface, south of S-112. The purpose of this survey was to establish the bulk resistivity of the soils around S-112.

\section{Methodology}

We used the resistance measurements made around S-112 and the Mock Tank together with numerical forward and inverse models to estimate the effective electrical resistivity of the tank. We have used several approaches to calculate the estimate:

1) Comparisons between the measured data and calculated data for a range of contrasts (tank to soil). The tank to soil contrast that produced the smallest RMS difference should identify the most likely resistivity for the tank. A 3D finite difference technique was used to calculate the predicted potential fields.

2) Inversion of the measured data to produce tomographic images of the tank resistivity. These inversions were made in a variety of ways (e.g. different starting models, different electrode configurations) to get a range of values that cluster 
around a center value. The range of values within a cluster gives a coarse estimate of the error in this analysis.

3) Using the values established for the resistivities of both tanks and their respective numerical models, we calculated the current densities that should be observed under each tank. We then compared the current densities under each tank to estimate differences in sensitivities that may be expected due to differences in spatial scale and electrical resistivities.

\section{Discussion of Results}

\section{S112 - forward calculations for a range of tank to soil resistivity contrasts}

With this method we used the 7 electrode surface array to calculate a typical soil resistivity for the site. We then used this typical value in a 3D finite difference model to calculate potentials at each long electrode in the survey around S-112. A simple comparison of measured potentials and calculated potentials on each electrode reveals how the model matches reality. Figure 2 and 3 show these comparisons. The model accounts for S-112 and the three adjacent tanks, and assumes a given effective resistivity for the tanks and a uniform resistivity for the remaining volume. We note that the effective tank resistivity is that due to the metal shell, any coating on the shell (tar, cement, etc.) and contact resistance at the metal interface. This effective resistivity is of interest here because the resistance measurements made are sensitive to the presence of all these materials.

When only the 9 dry wells are used as electrodes, the best fit to the data was for a tank less resistive than the soil by a factor of 100 or more. The method is not sensitive to values of the tank that are less resistive than this. The analysis sets the tank resistivity at $10^{-2} \mathrm{ohm} \mathrm{m}$ or less (see Figure 2). When the thermocouple tree was added to the receiver electrodes, the tank values could be less than $10^{-2}$ to $10^{\circ} \mathrm{ohm} \mathrm{m}$ (Figure 3 ). This range of values is to be expected in this type of analysis because limited data are available.

In summary, this approach indicates that S112 is at least 100 times less resistive than the surrounding soil but we cannot tell if the electrical contrast is even greater than this.

\section{S112 - Tomographic inversions - long electrodes}

With this method we use data from the electrodes at S112 to invert for values of tank resistivity assuming that we know the soil resistivity and the location and shape of the tank (i.e., we know the top and bottom boundary location). Analysis is done for two different starting models (soil to tank contrasts of 1:1 and 1000:1) and for data with (Figure 5) and without (Figure 4) the thermocouple tree as one of the electrodes. The results were very uniform, for the most part predicting a tank resistivity between $10^{-2}$ to $10^{-1} \mathrm{ohm} \mathrm{m}$. Soil resistivity was constrained at $200 \mathrm{ohm} \mathrm{m}$. 
In Figure 5, where the tank is used as an electrode, note that the reconstruction tends to yield a tank outline rather than a solid body as in Figure 4, where only dry wells were used as electrodes. Figure 5 shows a reconstructed tank that is a conductive shell in-filled with relatively resistive material. The reconstruction using only the 9 dry wells (Figure 4) finds a uniformly resistive tank because the tank walls are so conductive that no current can flow inside the tank. Where no current flows the method has no sensitivity-i.e., the search algorithm cannot determine what the internal resistivity is. This is a pathological case. The algorithm is constrained to find the smoothest possible solution, one in which the tank volume is uniform and equal to the value at the tank wall. When an electrode is placed within the tank, the inversion algorithm has more information. If the electrode is in good contact with the tank walls (i.e., a highly conducting material connects the electrode and walls) the algorithm will find the smoothest solution and produce a result similar Figure 4. On the other hand, if the electrode in the tank is not in good contact with the liquid (resistance is comparable to that between a dry well and the tank) the algorithm will be forced to disconnect that electrode and the tank and the only way it can do this and satisfy the smoothness constraint is to make the inside of the reconstructed tank more resistive (as in Figure 5).

The lesson to learn from this result is that the thermocouple tree is not in good electrical contact with the tank contents (perhaps the tree is imbedded in dry salt-cake). This result is important for any leak detection method that requires a thermocouple tree in good electrical contact with the tank steel walls to carry current to a leak point. It is likely in S-112 that the thermocouple tree is not now in good electrical contact with the tank and that contact will change as the water content of the salt cake changes during waste retrieval. In other words, measurements that use the thermocouple tree as an electrode will be sensitive to resistivity changes within the tank walls (e.g. waste retrieval water changing the moisture content of the waste) and outside of the tank (tank fluids invading the soil around the tank).

\section{Mock Tank - Tomographic inversions - point and long electrodes}

The goal of this study is to compare the properties of S-112 and the Mock Tank. In order to be able to do the comparison, we have processed some of the data from the Mock Tank tests last summer in a similar manner to the S-112 analysis presented above. Figure 6 shows reconstructions of the Mock Tank site using point electrodes, with and without the tank as an electrode. The results are similar in the two cases and show that the tank effective resistivity is between $10^{0.5}$ and $10^{1} \mathrm{ohm}-\mathrm{m}$.

When the long electrode data are used (see Figure 7) the tank resistivity is between $10^{-0.5}$ and $10^{+0.5} \mathrm{ohm} \mathrm{m}$. The long electrode results are weakly dependent on the starting model and require fixing the soil at $600 \mathrm{ohm} \mathrm{m}$. 


\begin{tabular}{|c|c|c|}
\hline S-112 Results & $\begin{array}{l}\text { Resistivity } \\
\text { estimated based on } \\
\text { forward } \\
\text { calculations }(\mathrm{ohm}-\mathrm{m}) \\
\end{array}$ & $\begin{array}{l}\text { Resistivity estimated based on } \\
\text { inverse calculation } \\
\text { (tomograph) }(\text { ohm }-\mathrm{m})\end{array}$ \\
\hline Data from 9 dry wells & $10^{-2}$ & \\
\hline $\begin{array}{l}\text { Data from S-112 } \\
\text { thermocouple tree }+9 \text { dry } \\
\text { wells }\end{array}$ & $10^{-2}$ to $10^{0}$ & \\
\hline $\begin{array}{l}\text { Data from } 9 \text { dry wells, } \\
\text { Starting contrast }=1: 1\end{array}$ & & $10^{-2}$ to $10^{-1}$ \\
\hline $\begin{array}{l}\text { Data from } 9 \text { dry wells, } \\
\text { Starting contrast }=1: 1000\end{array}$ & & $10^{-2}$ to $10^{-1}$ \\
\hline $\begin{array}{l}\text { Dat from S-112 } \\
\text { thermocouple tree }+9 \text { dry } \\
\text { wells, } \\
\text { Starting contrast }=1: 1\end{array}$ & & $10^{-2}$ to $10^{0}$ \\
\hline $\begin{array}{l}\text { Data from } S-112 \\
\text { thermocouple tree }+9 \text { dry } \\
\text { wells, } \\
\text { Starting contrast }=1: 1000\end{array}$ & & $10^{-2}$ to $10^{-1}$ \\
\hline Mock Tank Results & $\begin{array}{l}\text { Resistivity } \\
\text { estimated based on } \\
\text { forward } \\
\text { calculations }(\mathrm{ohm}-\mathrm{m}) \\
\end{array}$ & $\begin{array}{l}\text { Resistivity estimated based on } \\
\text { inverse calculation } \\
\text { (tomograph) (ohm-m) }\end{array}$ \\
\hline $\begin{array}{l}\text { Data from } 128 \text { point elec }+ \\
\text { tank }\end{array}$ & & $10^{0.5}$ to $10^{1}$ \\
\hline Data from 128 point elec & & $10^{0.7}$ \\
\hline $\begin{array}{l}\text { Data from } 16 \text { long elec, } \\
\text { Starting contrast = 1:1000 }\end{array}$ & & $10^{-0.5}$ to $10^{0.5}$ \\
\hline $\begin{array}{l}\text { Data from } 16 \text { long elec, } \\
\text { Starting contrast = } 1: 1\end{array}$ & & $10^{0}$ to $10^{0.5}$ \\
\hline
\end{tabular}

Table 1 summarizes the estimates of effective electrical resistivity for the S-112 and Mock Tanks.

\section{Summary and Conclusions}

We have used electrical resistance data collected near the S-112 and Mock Tanks to estimate the effective electrical resistivity of each tank, and to compare sensitivities of long electrode measurements to the sediment electrical resistivity under each tank. Due to the assumptions we had to make and the approximations used, we consider these results to be approximate but believe that reliable conclusions can be made about the relative electrical properties of the tanks. 
We used a variety of methods to estimate the tanks' resistivity. The results of the various methods are summarized in Table 1 . The S-112 results range from $10^{-2}$ to $10^{0} \mathrm{ohm}-\mathrm{m}$, and the most likely value is probably $10^{-1} \mathrm{ohm}-\mathrm{m}$. Similarly, the Mock Tank values range from $10^{-0.5}$ to $10^{1} \mathrm{ohm}-\mathrm{m}$; we have picked a value near the middle of this range $\left(10^{\circ} \mathrm{ohm}-\mathrm{m}\right)$ as the most representative value for the Mock Tank. These results suggest that the S-112 and Mock Tank resistivities are about an order of magnitude different, and that $\mathrm{S}-112$ is more conductive than the Mock Tank.

We note that the estimated resistivities are much larger than those of fresh carbon steel $\left(10^{-8} \mathrm{ohm}-\mathrm{m}\right)$. Both tanks are steel construction and should be more or less electrically equivalent except for important construction details such as coatings on the steel (tar paper, rust) and soil-metal contact resistance. We believe these details dominate the results we report.

The data indicate that S-112 appears more conductive than the Mock Tank by a factor of about 10. This implies that the tar coating on S-112 is no longer resistive or that the concrete top is dominating the response. The results also imply that the contact impedance of the Mock Tank is relatively high, most probably due to very dry soil at shallow depths and/or rust on the metal.

This finding also implies that sensitivity results from the Mock Tank tests will not be directly applicable to S-112. Since S-112 is more conductive and it presents a larger volume than the Mock Tank, more current will be shunted away from the region of interest below the tank, especially for long electrode work. Therefore, for a given source current, the current density below S-112 will be lower than below the Mock Tank and this translates into a lower sensitivity to changes in resistivity below S-112.

This principle is illustrated in Figure 8 where we compare the calculated current density for the two sites. The calculations show that the current density is about 3 times larger at the bottom center (the worst case) of the Mock Tank than in that location at S-112. While this is not a surprising result, we do believe that the Mock Tank results from this summer will be approximately three times more sensitive to leaks as will S-112 results during waste retrieval.

The current density differences are caused by two factors: (a) the differences in effective resistivity and size of each tank and (b) the difference in electrode separation and electrode length in the two cases. Contributions from these effects are separated by comparing current density for the two cases with the tanks present (Figure 8) and without the tanks present (Figure 9) in the model calculations. Without the tanks, the current density just below where the tanks would have been is about 3 times larger at the Mock Tank site than at S-112. When the tanks are present the current density is more than 5 times higher at the Mock Tank site.

However, the important conclusion is to be made by considering the two factors together, which is that the current density below the Mock Tank is about 5 times higher than beneath $\mathrm{S}-112$. Therefore, we conclude that using long electrode data, sensitivity to a 
conducting plume will be about 5 times larger at the Mock Tank site than at S-112 and that this difference should be a factor in applying results from tests this summer to any quantitative conclusions during waste retrieval.

We have also determined that the thermocouple tree in S-112 is likely to be in poor electrical contact with the tank contents and tank wall. One possibility is that the structure is imbedded in a dry, resistive salt-cake. If we use the thermocouple tree as an electrode, the coupling between it and the tank walls will change during the waste retrieval operation as the salt-cake is eroded and takes up water. This means that the measurements will be sensitive to changes in resistivity occurring within the tank as well as in the soil around the tank. The possibility of a false-positive prediction increases because of this dual sensitivity. 
Figures: 

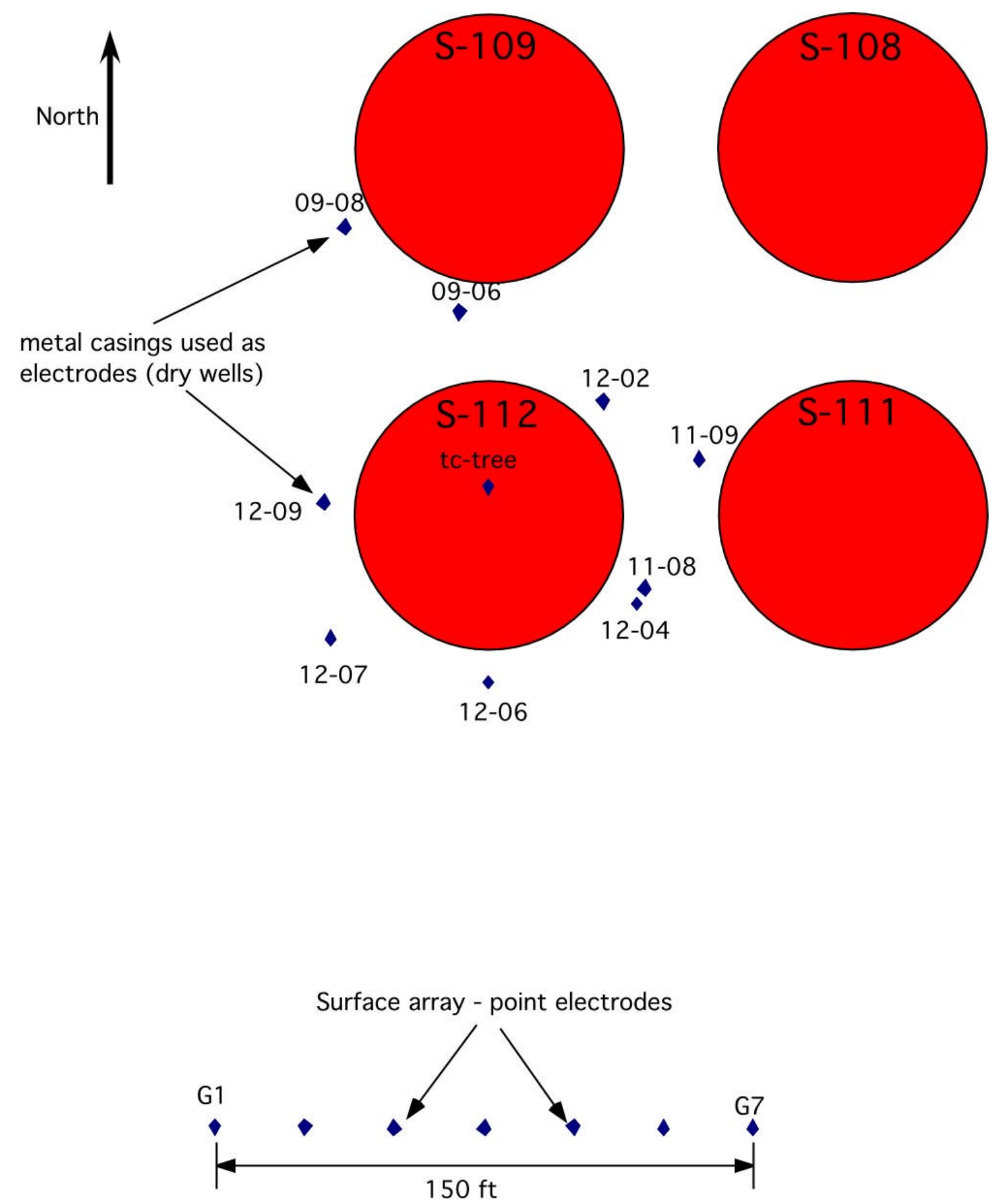

Figure 1. The location of the dry wells and thermocouple (tc) tree used as electrodes is shown. Only the dry wells and trees used to collect the data discussed in this report are shown. Also shown are surface (point) electrodes used to measure the bulk resistivity of the sediments near S-112. 


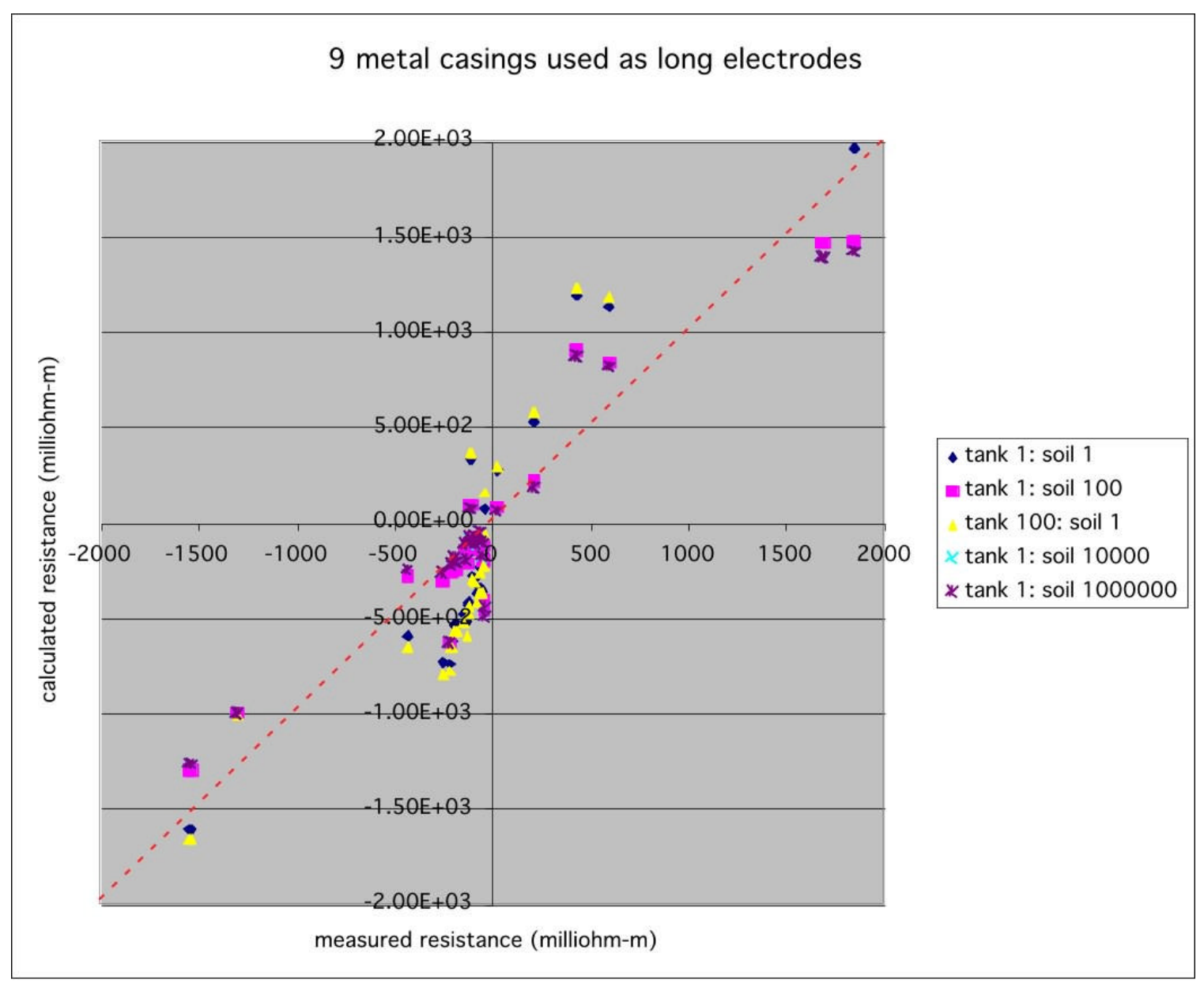

\begin{tabular}{|l|r|}
\hline Resistivity contrast (tank to soil) & root mean square difference \\
\hline 100 to 1 & 353.4 \\
\hline 1 to 1 & 314.5 \\
\hline 1 to 100 & 139.5 \\
\hline 1 to 10000 & 138.6 \\
\hline 1 to 1000000 & 138.6 \\
\hline
\end{tabular}

Figure 2 compares the measured and calculated data for various resistivity contrasts. In this case 9 dry wells were used to collect the data. The dashed red line indicates where the points would plot if there was perfect agreement between the measurements and the calculations. Also shown are the sums of the root mean squared (RMS) differences for the various plots. Note that the RMS sum reaches a minimum when the contrast is 1:10000. 


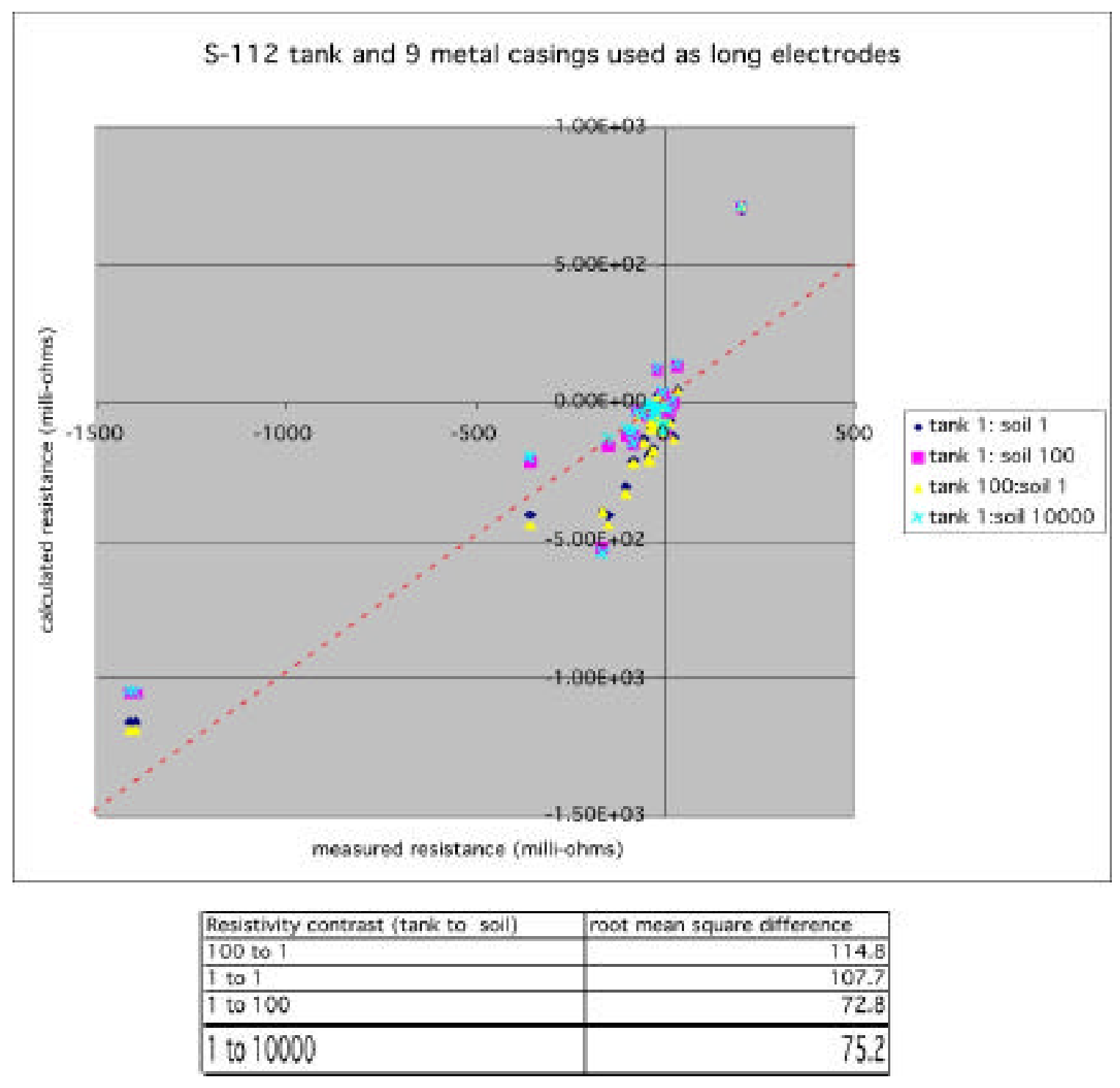

Figure 3 compares the measured and calculated data for various resistivity contrasts. In this case the thermocouple tree in S-112 plus 9 dry wells were used to collect the data. The dashed red line indicates where the points would plot if there was perfect agreement between the measurements and the calculations. Also shown are the sums of the root mean squared (RMS) differences for the various plots. Note that the RMS sum reaches a minimum when the contrast is 1:100 but the values for the 1:10000 case is very similar. 


\section{Reconstruction of S112 Tank Electrical Resistivity using data from 9 dry wells}

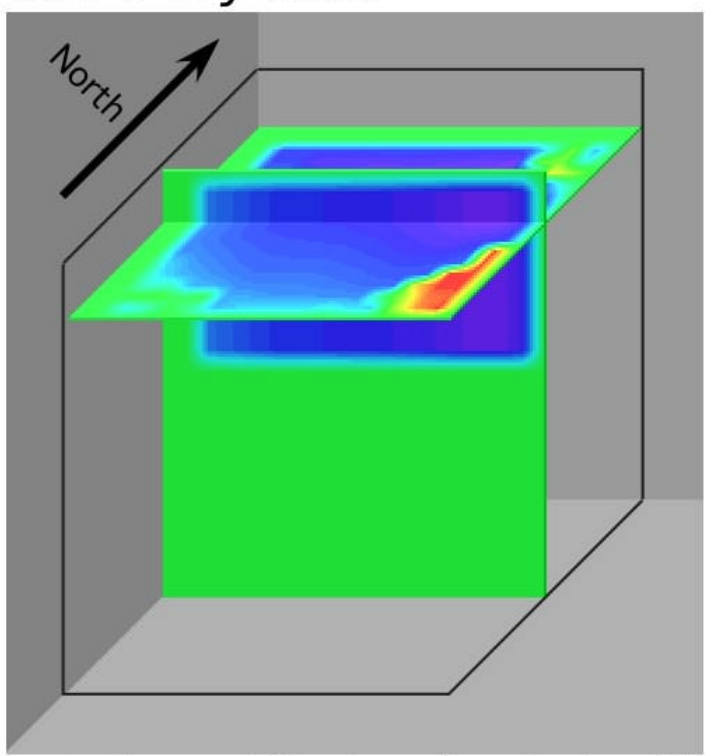

starting model tank : soil contrast $=1: 1$

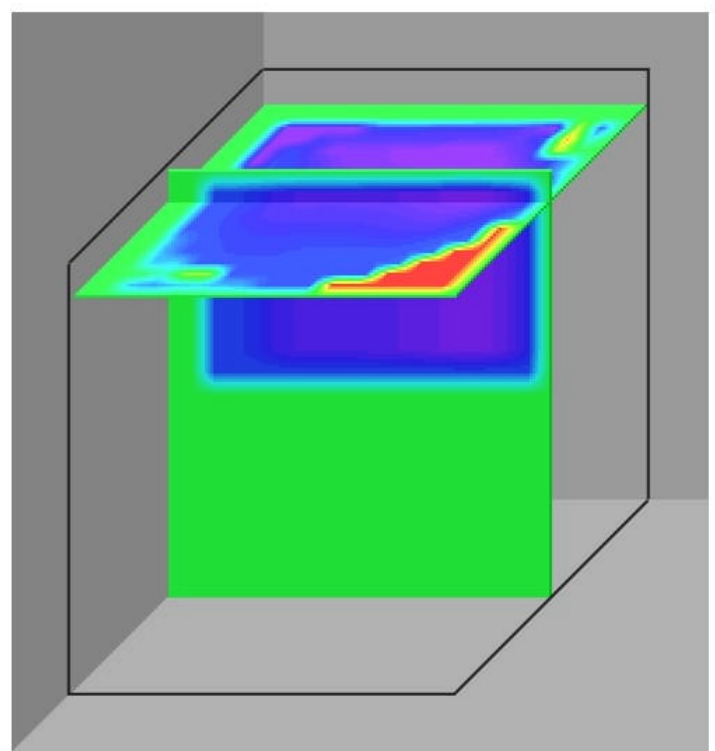

starting model tank : soil contrast $=1: 1000$

\section{$\log 10$ resistivity (ohm-m)

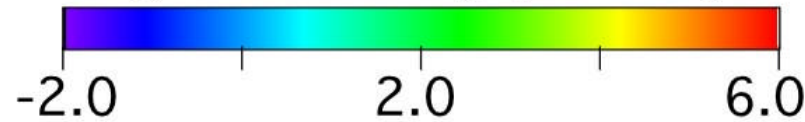

Reconstruction parameters:

1) initial condition - as specified above

2) location of tank is specified and its resistivity is allowed to change

3) sediment resistivity is fixed at $200 \mathrm{ohm}-\mathrm{m}$

Figure 4 compares two tomographs showing the resistivity for S-112. In this case, 9 dry wells were used to collect the data. Two starting models were assumed for the inversions: for the left tomograph, the tank to soil resistivity contrast is $1: 1$; for the right tomograph the contrast assumed is 1:1000. The inversions were constrained to change the electrical resistivity only in the depth range occupied by the tank. The properties of the surrounding sediment remained fixed at $200 \mathrm{ohm}-\mathrm{m}$. 


\section{Reconstruction of S112 Tank Electrical Resistivity using data \\ from S-112 thermocouple tree and 9 dry wells}

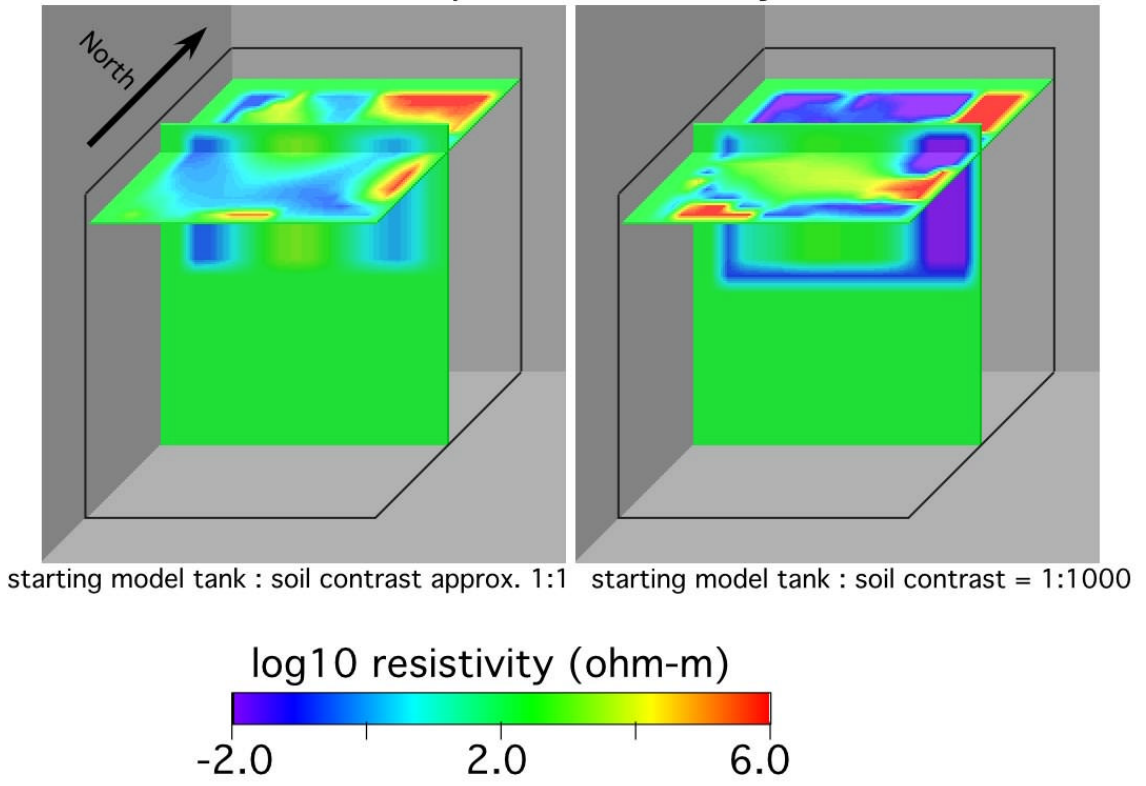

Reconstruction parameters:

1) initial condition - as specified above

2) location of tank is specified and its resistivity is allowed to change

3) sediment resistivity is fixed at $200 \mathrm{ohm}-\mathrm{m}$

Figure 5 compares two tomographs showing the resistivity for S-112. In this case, the S112 thermocouple tree and 9 dry wells were used to collect the data. Two starting models were assumed for the inversions. For the left tomograph, the tank to soil resistivity contrast is 1:1; for the right tomograph the contrast assumed is 1:1000. The inversions were constrained to change the electrical resistivity only in the depth range occupied by the tank. The properties of the surrounding sediment remained fixed at $200 \mathrm{ohm}-\mathrm{m}$. 


\section{Reconstruction of Mock Tank Electrical Resistivity}

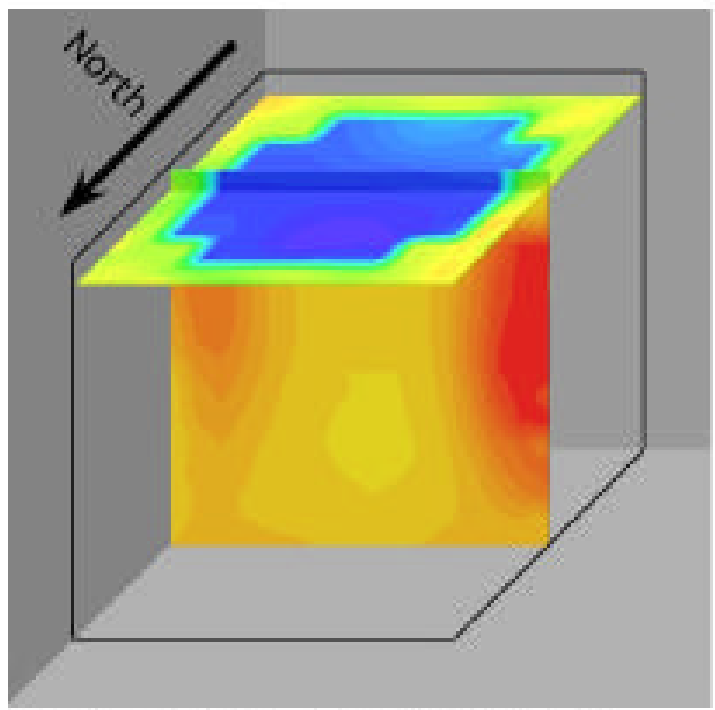

tank +128 point electrodes used

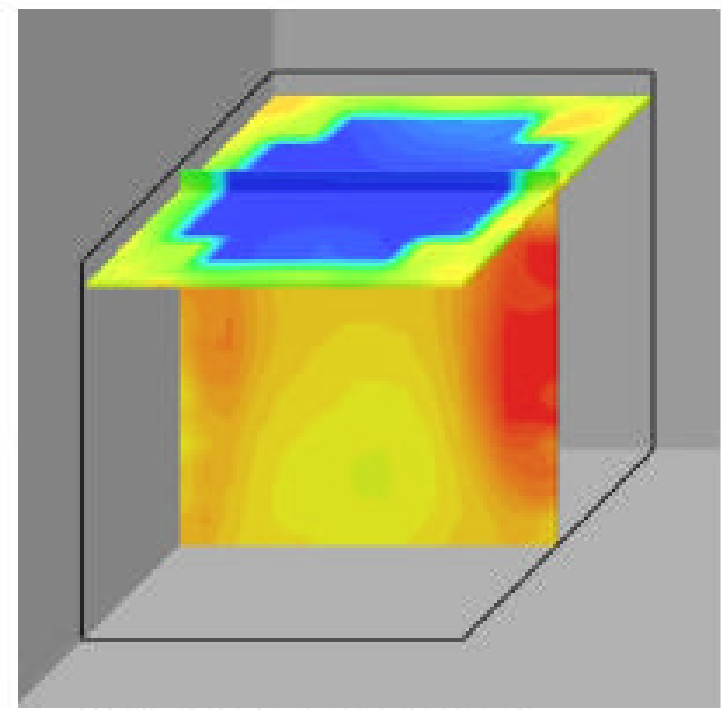

128 point electrodes used

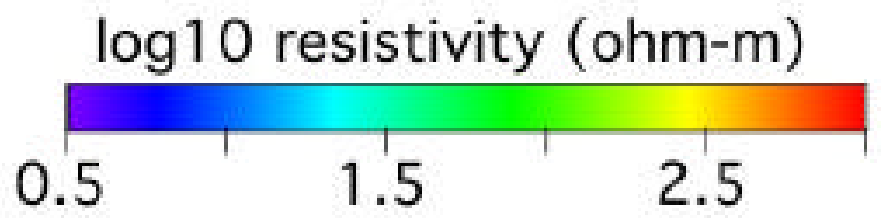

Reconstruction parameters:

1) initial condition - homogeneous half-space with a resistivity of $1000 \mathrm{ohm}-\mathrm{m}$

2) location of tank is specified and its resistivity is allowed to change

3) sediment resistivity is allowed to change

Figure 6 compares two tomographs showing the resistivity for The Mock Tank. For the left tomograph, the tank was used as an electrode together with 128 point electrodes; for the right tomograph, only data from the 128 point electrodes was used. The properties of the tank and surrounding sediments were allowed to change. 


\section{Reconstruction of Mock Tank Electrical Resistivity using data from 16 long electrodes}

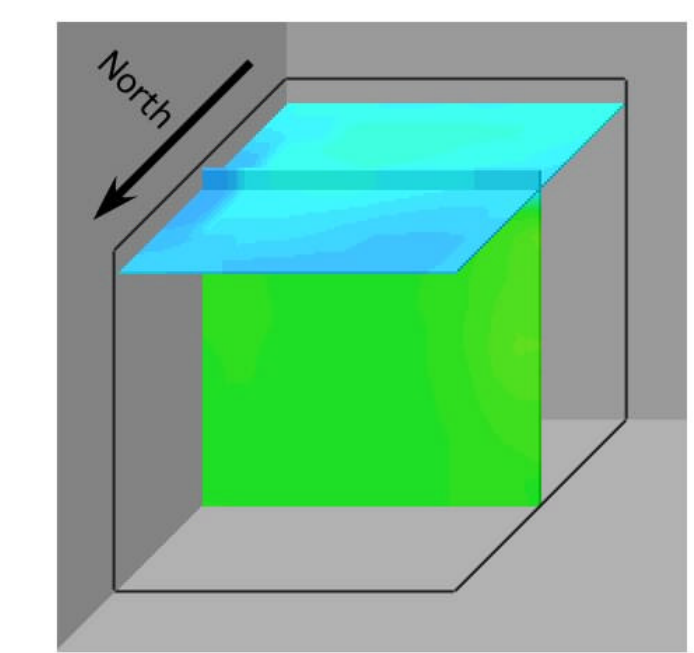

starting tank : soil contrast approx. 1:1

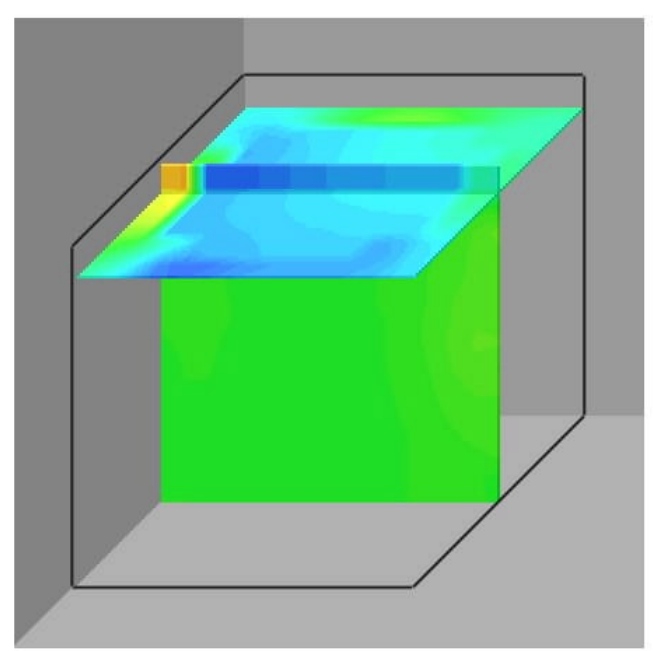

starting tank : soil contrast approx. 1:1000

\section{$\log 10$ resistivity (ohm-m)

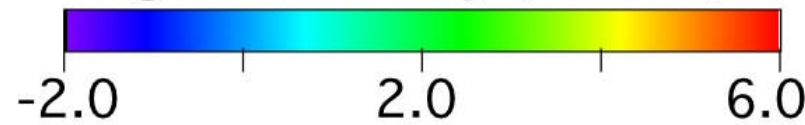

Reconstruction parameters:

1) initial condition - as specified above

2) location of tank is specified and its resistivity is allowed to change

3) sediment resistivity is fixed at approximately $600 \mathrm{ohm}-\mathrm{m}$

Figure 7 compares two tomographs showing the resistivity for The Mock Tank. In this case, 16 long electrodes were used to collect the data. Two starting models were assumed for the inversions. For the left tomograph, the tank to soil resistivity contrast is $1: 1$; for the right tomograph the contrast assumed is 1:1000. The inversions were constrained to change the electrical resistivity only in the depth range occupied by the tank. The properties of the surrounding sediment remained fixed at approximately $600 \mathrm{ohm}-\mathrm{m}$. 


\section{Current distribution under the S-112 and Mock Tanks}

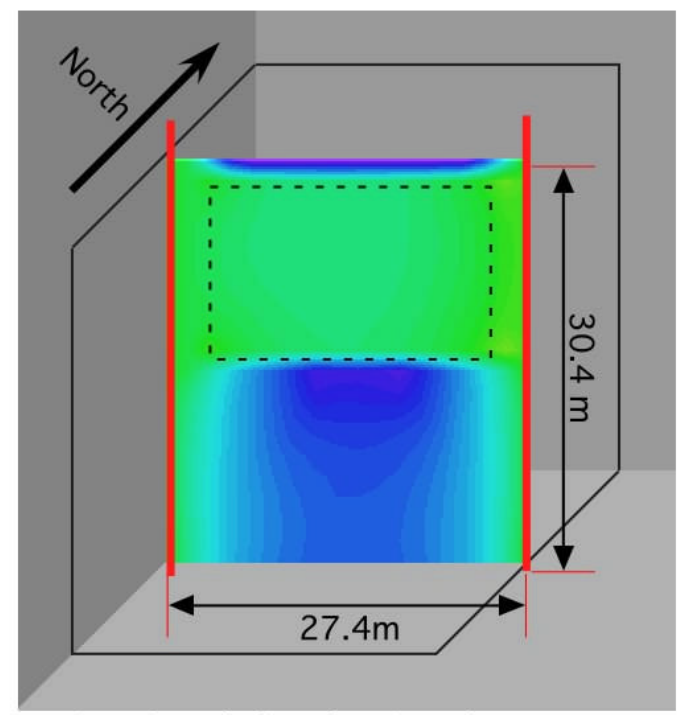

S-112 tank $($ tank $=0.1$ ohm-m, soil $=200 \mathrm{ohm}-\mathrm{m})$

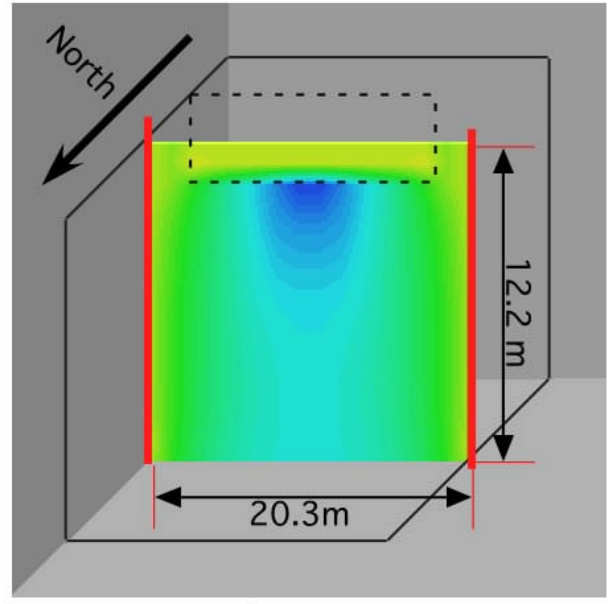

Mock tank ( tank $=1$ ohm-m, soil $=600$ ohm $-\mathrm{m})$

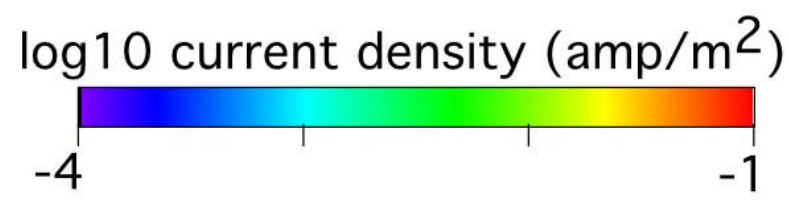

: . . tank outline

long electrode location
Model parameters:

1) tanks modeled as solid structures

2) long electrodes inject $1 \mathrm{amp}$ of current

Figure 8. Calculations of current density beneath S-112 and the Mock Tank from long electrodes diametrically opposed and producing 1 amp of current. The electrical resistance measurements are most sensitive to regions showing the highest current density. Based on these calculations, we expect higher sensitivities at the Mock Tank site. 


\section{Current distribution at the S-112 and Mock Tanks sites when the tanks are not present}

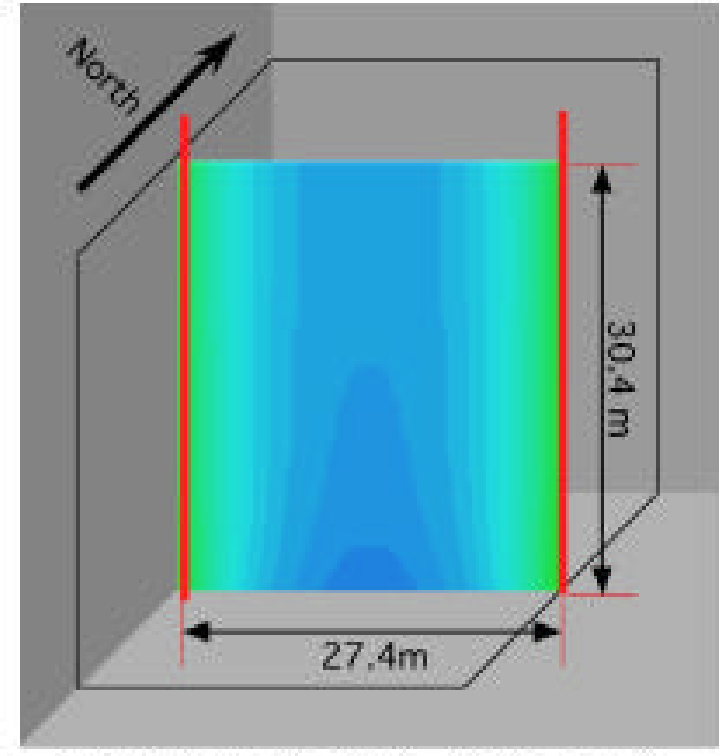

S-1 12 tank site (soil $=200$ ohm-m)

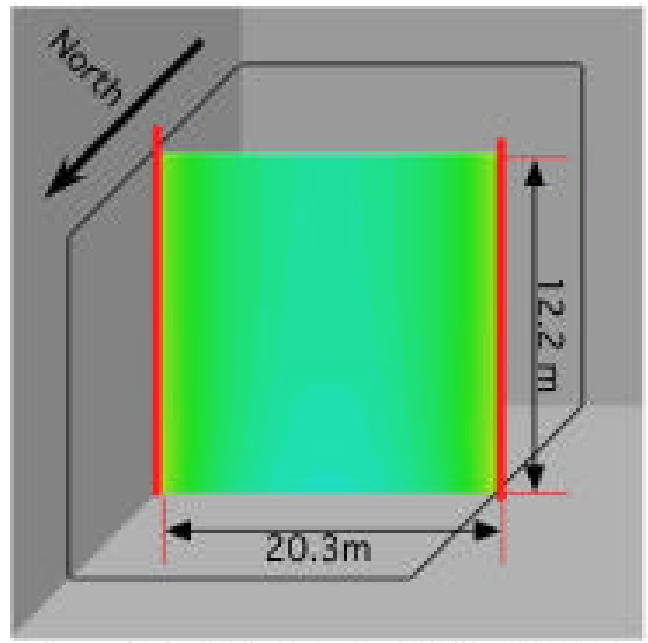

Mock tank site (soil $=600$ ohm-m)

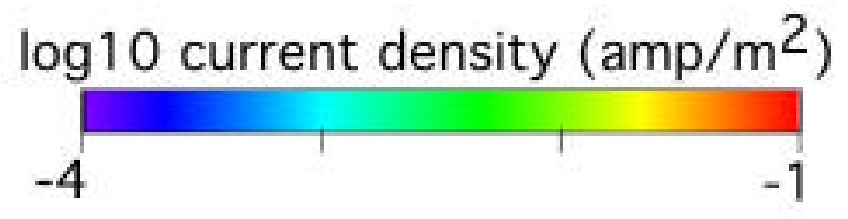

long electrode location

Model parameters:

1) tanks removed from the problem

2) long electrodes inject 1 amp of current

Figure 9. Calculations of current density when the tanks are removed from the problem. Other parameters as indicated for Figure 8. The electrical resistance measurements are most sensitive to regions showing the highest current density. Based on these calculations, we expect higher sensitivities at the Mock Tank site. 